\title{
Prosthetic restoration of the canine
}

\author{
Pascal AUROY, Jean LECERF
}

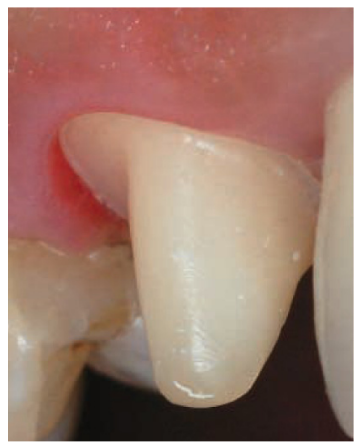

\section{ABSTRACT}

There are many ways dentists can restore teeth prosthetically. Depending on its condition of relative integrity or more serious breakdown and the patient's loss of other teeth, the practitioner can choose from a variety of quite different procedures ranging from the fabrication of a single ceramo-ceramic crown on a vital tooth to correction of considerable loss of teeth with an implant supported bridge. This paper will evaluate most of these treatment modalities and, in addition to purely prosthetic considerations, will discuss the integration into treatment of periodontal, implant, occlusal, and functional concepts.

\section{KEYWORDS}

\author{
Prosthesis \\ Dental occlusion \\ Oral rehabilitation \\ Canine.
}




\section{1 - INTRODUCTION}

Dentists should view the prosthetic restoration of a canine tooth as a process that is situated at the confluence of occlusal, functional, mechanical, aesthetic, periodontal, and surgical imperatives. In this light we shall pass into the territories of related specialties when certain specific points of their domain clearly have an impact on the therapeutic success of our prosthetic therapy. But the subject is vast and we have no intention of covering it in an exhaustive fashion because to that we should have had to embrace the quasi-totality of prosthetic dentistry. Nor have we planned to present a catalogue of the traditional therapies pigeon-holed into the habitual subdivisions of our specialty but, instead, to offer some thoughts devoted to the canine tooth organised in relation to its deterioration, its absence, and to the extent of the edentulousness that sometimes accompanies those unhappy developments.

We have prepared an abundant presentation of illustrations to vivify the concepts that have arisen from our introspections. We hope that our colleagues in dento-facial orthopaedics, whose interest in dental prosthetics we share, will find in these pages the synthesis they anticipated.

\section{2 - RESTORATION OF A SINGLE BROKEN DOWN CANINE TOOTH}

Our first thoughts on the restoration of single deteriorated canine teeth focus on those that have managed to remain vital despite the serious depredations caused by decay or trauma.

The protocols for the preparation of a fixed prosthesis placed on a vital tooth have been codified for many years ${ }^{56}$. Dentists primarily make their decision about a keeping a canine tooth vital or treating it endodontically before rehabilitating it prosthetically on the basis of an evaluation of the health of the pulp and of a periapical X-ray. Dentists prepare the tooth under a water spray using sharp new rotary instruments. They make the temporary crown by thoroughly cooling the thermally cured plastic, eventually taking advantage of the openings of dentinal tubules to gain its reliable retention as well as that of the permanent crown that will indefinitely preserve all of the tooth's mechanical and biological potential ${ }^{56}$. (fig. 1 and 2). In every case the temporary crown protects the prepared crown during the indispensable several week rest period (fig. 3) needed before the permanent crown (fig. 4) can be cemented.

For experienced practitioners who follow the protocols we have outlined the failure rate, defined as inflammation or necrosis of the pulp that would require endodontic intervention, is about the same as the failure rate of economic treatment itself. The endodontic of health care service indicate to us that no matter what the precise failure rate of the two concepts may be, the practitioner who routinely performs endodontic treatment on all teeth that are candidates 

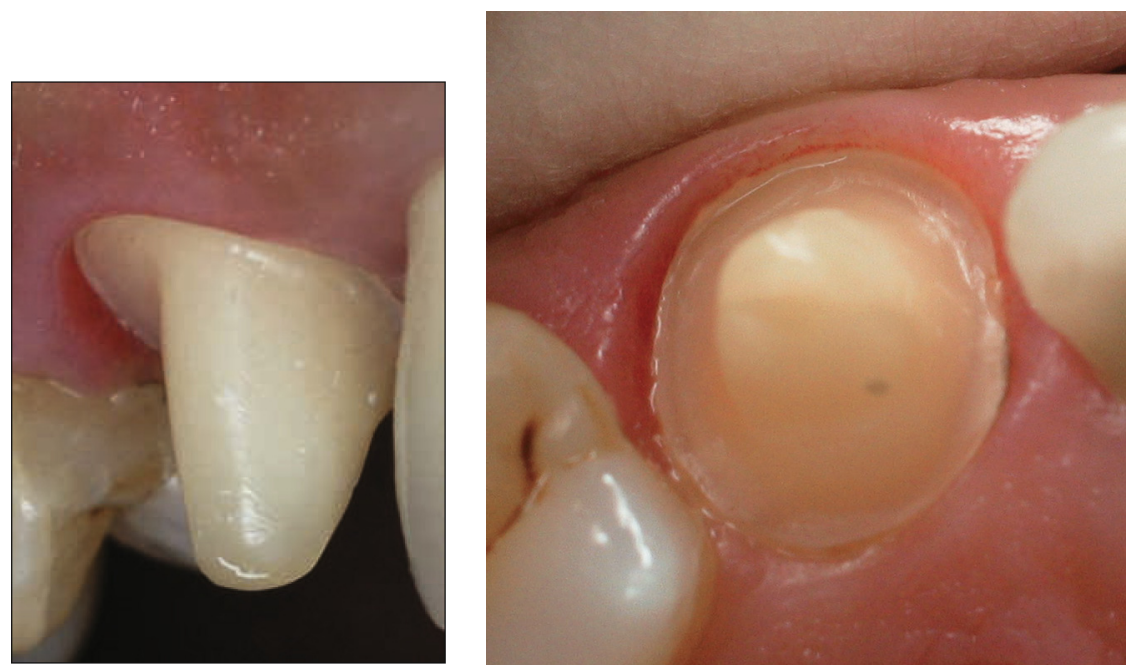

Figures 1 and 2

Preparation of a maxillary canine for a ceramo-ceramic crown: in view of the considerable amount of dentine that must be removed in order to make room for the ceramo-ceramic crown and cosmetic cover, the clinician must follow protocol scrupulously in order to preserve the tooth's vitality indefinitely.

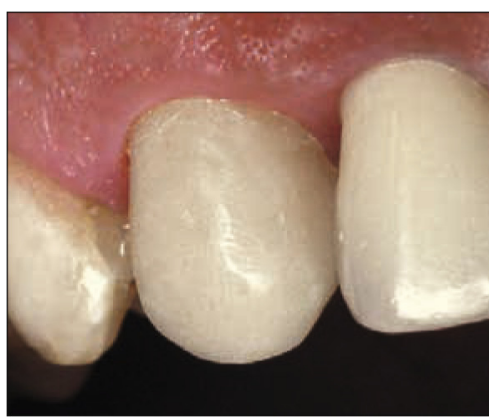

Figure 3

A temporary crown will protect the tooth during the indispensable several week rest period while the permanent crown is being fabricated.

for crowns, whether they are vital or not, will, from the simple mathematics of the matter, extract more teeth because of failure than a colleague who preserves the vitality of selected teeth in preparing them for crowns. Let us remember that dentists should prepare affected teeth in accordance with accepted procedure, using appro-

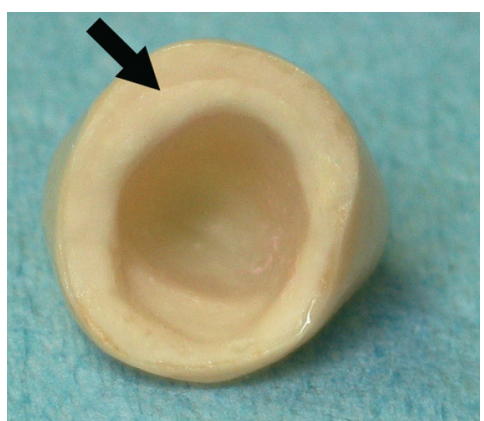

Figure 4

View of the under-side of a ceramo-ceramic aluminum Vita Inceram. Note the cosmetic/ tooth periphery and the arrow indicating the visible demarcation between the aluminum and the cosmetic ceramic covering it

priate filling materials on vital teeth when indicated.

But if the diagnosis shows that a tooth's vitality has already been compromised, or that the pulp is so large that the required reduction of the tooth's hard tissue to accommodate the bulk of the restoration will endanger it, 
endodontic treatment becomes necessary as well as a reconstruction of crown and root.

At this point the dentist and patient must decide on the type of construction of the crown. Should it be cast as is done for the traditional inlay-core procedure or milled? Indications for this newer type of milled restoration are now also perfectly well codified ${ }^{1}$ : presence of the three elements of a tooth's hard structure of at least $1 \mathrm{~mm}$ in thickness and a height greater than half of the proposed prosthetic crown. The removal of tooth substance should never enter into the sulcus space so that clinically the junction between crown and tooth can be hidden in the sulcus and encircling dentinal structure. Finally, more for canines than for other teeth, the rule of dentists having have good accessibility in preparing it and maintaining it in complete isolation from the fluids of the oral cavity in bonding or cementing it is an indispensable requirement for success ${ }^{1,5,8}$.

With these points in mind, we believe that milled crown-root rehabilitation is contra-indicated and that a cast reconstruction ${ }^{21,25,50}$ is required. No matter what material is employed in fabrication the proper preparation for the root post will demand reduction of the root walls to less than $1 \mathrm{~mm}$ in thickness and the removal of a considerable amount of dentine.

Because the modules of elasticity of the metal making up the cast replacement crown and root are 10 to 30 times greater than those of the natural dentine itself, occlusal constraints are transmitted almost in full force to the root structures. That is why it is best to select materials with weak modules of elasticity, which is why dentists should not utilise zircon, oxide of zirconium, whose module of elasticity is 60 times greater than that of dentine.

In order to understand this problem well, we must consider the flow of constraints at the interface of the prosthesis and the dentine: for a given amount of occlusal forces, the larger the surface of the interface the more widely and thus less densely, the forces are distributed. So the practitioner should increase the size of the preparation in the root as much as possible thus increasing the amount of dentine that will contact the inserted post. But this must be done by making the preparation longer, not wider, because that would reduce the thickness of the dentinal walls and make them more fragile. Thus we keep the bore of our preparations, and, accordingly the diameter of the posts that will fit into them, as narrow as possible, but of lengths equal to $2 / 3$ to $3 / 4$ of the depth of the alveolus in which the tooth's root resides $^{11,12,30,36}$. (fig. 5).

We bond the inlay-core rather than cement it, thus reinforcing the attachment of the prosthesis to the root and encouraging the diffusion of occlusal constraints ${ }^{1,10,11,12}$. All these modalities are particularly pertinent to canine teeth, in view of the heavy nature of the occlusal forces to which they are subjected. By carefully following the preparation protocol we have suggested, practitioners can reduce the risk of a prosthesis on a canine tooth becoming uncemented or debonded or of the tooth's root being fractured.

In order to make prosthetic crowns placed on canine teeth aesthetically satisfactory the best materials for 


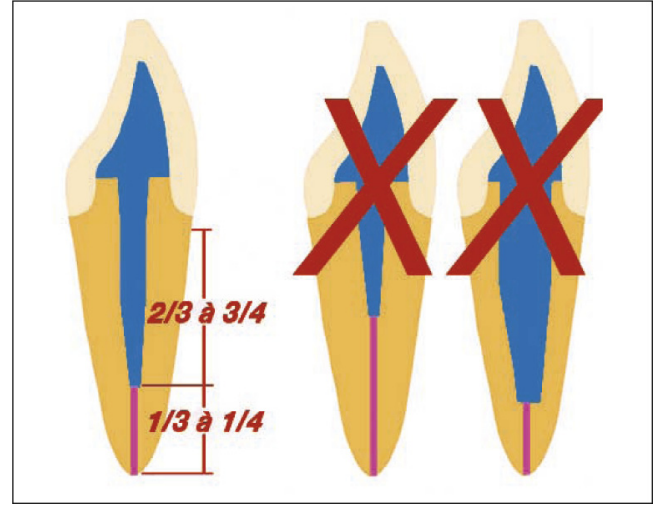

Figure 5

We believe that it is important for the posts be narrow in diameter but long enough to equal $2 / 3$ to $3 / 4$ of the length of the root.

dentists to choose are ceramo-ceramic for vital teeth and ceramo-metallic for endodontically treated canines whose preparation has not been aesthetically oriented $^{2,13,46,48,52}$.

A primordial requirement for any prosthetic rehabilitation is that the involved teeth must be invested in a healthy periodontal environment, that is that the periodontal fibers be sturdy and free from inflammation. In order to maintain them in that condition, the dentist's tooth preparation should be entirely supra-gingival except where the circumference of the crown will be directly visible or when existing sulcular lesions or contours force the practitioner to place the junction of crown and tooth within the sulcus. In these situations the dentist should respect the principles that Gaarguilo ${ }^{22}$ proposed in a 1961 article. The position of the edges of the prosthesis should respect the epithelium of the junction by preserving a margin of error. They will not be tolerated unless they are set at a minimum distance .4 $\mathrm{mm}$ from leading edge cells of the epithelial attachment. Accordingly, prosthesis should never be set more deeply than $.5 \mathrm{~mm}$ in a sulcus $1 \mathrm{~mm}$ in depth. There is today a strong consensus that with junctions of prosthesis to tooth of equal quality those that are placed more deeply in the dento-alveolar sulcus will provoke the most inflammatory reactions $^{15,19,20,22,32,40,51,55}$.

Preferably, dentists should make the buccal aspect of a rehabilitated canine one of a ceramico-tooth junction rather than one that is metallictooth, for obvious aesthetic reasons. This is rapidly becoming the standard approach because modern well formulated techniques allow for an excellent cervical adaptation, of less than 80 microns (cf. fig. 30). Nowadays, the tooth-prosthesis buccal or labial junctions of ceramo-ceramic crowns can be virtually invisible and are placed very slightly, $.3 \mathrm{~mm}$, beneath the sulcus or at the gingival level because they have no unattractive metal beneath their outer surfaces $40,51,55$.

To prepare teeth properly for ceramo-metallic crowns with tooth prosthesis joints that are ceramic as well as for crowns that are entirely ceramoceramic, dentists must use large flame burs to make shoulders with rounded internal angles. The only distinction between the two types is the thickness of the preparation required, 1.2 to $1.8 \mathrm{~mm}$ for the first and .8 to $1.2 \mathrm{~mm}$ for the second. All other forms of preparation have now become outmoded because of new techniques, new materials, and modern prosthetic methods and matererials $^{16-18}$ (cf. fig. 1, 2). 


\section{3 - REPLACING MISSING CANINES}

Apart from orthodontic solutions, a missing maxillary permanent canine tooth is usually best replaced by a prosthetic crown placed on an implant. Generally speaking the intra-oral constraints that upper canines are subjected to, in lateral as well as in protrusive excursions make their restoration with a traditional bridge a delicate and questionable enterprise. A multi-unit bridge, for example anchored on premolar or incisal teeth should certainly not be considered as a proper restoration because of the likelihood that it will transmit iatrogenic traumatic forces to the periodontal membranes of the abutment teeth. In the same way a bridge having as its only abutments the premolar teeth and a lateral incisor

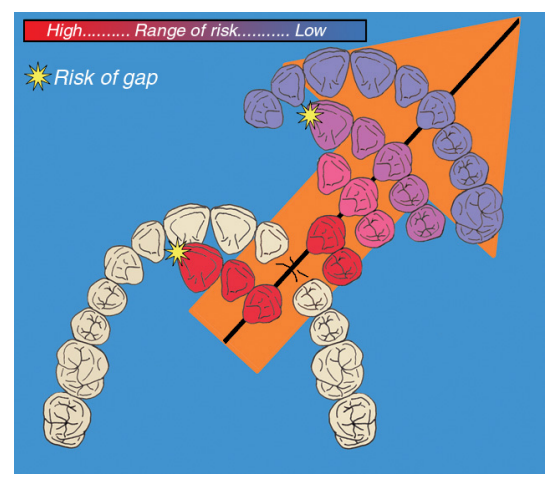

Figure 6

Replacing missing maxillary canines sometimes requires the construction of large multi-unit bridges. The powerful forces that act on them (depicted in the orange arrow) sometimes results in the opening up of an unattractive space when the bridge does not incorporate any dental units on the other side of the midline. The range of risk is shown within the arrow of a colored range scheme running from high risk in red to low risk in blue. will eventually cause the loss of the lateral because the root structure and investing periodontal tissues of this tooth resist lateral forces poorly. Extending the bridge to include the central incisor whose structural makeup is better suited to resist difficult occlusal stress rarely solves the problem because splinting together the premolars and the incisors of the same side imparts to those incisors a distal component of force which progressively opens up a mesial space or diastema.

These types of bridges succeed, despite this dire prognosis, on those rare occasions when the root support is especially robust and the occlusal constraints are especially feeble $42,49,53,54$. In general, the participation of the canine in disoccluding the posterior teeth in lateral and protrusive excursions makes it necessary for the dentist include in the reconstruction to replace a missing canine all the teeth from the premolars on the ipsilateral side and at least the central incisor, and possibly the lateral incisor and canine on the contralateral side (fig. 6). This extended type of rehabilitation is less indicated on the mandible because there lateral occlusal constraints are largely directed lingually and are distributed and dissipated through inter-arch contact points and into the supporting bone, which is far denser than maxillary bone ${ }^{49,53}$.

Finally, whatever form the bridge may take, bonded splints or cemented crowns, the obligatory inclusion of numerous abutments greatly complicates the fabrication of this type of rehabilitation of a missing canine and makes the 
choice of a crown placed on an implant a seductively attractive treatment plan, especially in the maxilla. ${ }^{23,43}$.

The surgical placement of a single implant to replace the root of a missing maxillary canine does not usually pose any problems. When a large amount of bone is available and the space between the first premolar and the lateral incisor is adequate, access is easy. But the surgeon must take care to position the implant exactly at the midpoint between the premolar and the lateral and somewhat palatally so as to leave a sufficient amount of gingival tissue in place to lend a natural appearance to the artificial tooth. This will also allow the prosthodontist to utilise an implant whose collar will be wider than the collar of the post and still leave enough space buccally for soft tissues. Unfortunately the buccal anatomy of the maxilla in the canine area when the tooth has been missing for any length of time is concave, often excessively above the area where the canine bulge ought to be. Because the quantity of bone palatally is always sufficient and they fear they will risk fenestration, if they place the implant too close to cortical buccal bone, oral surgeons are tempted to position their implants with the apex too far palatally, which often makes the pivot emerge too far buccally $6,7,9,14,26,47$ (fig. 7).

This type of emergence has serious undesirable aesthetic and health consequences for the soft tissues. So the prosthodontist and the oral surgeon should carefully analyse the computed tomographic films taken pre-operatively with a radio opaque radiological guide to plan the provisional orientation of the implant and its future emergence. The surgeon will then use the surgical guide to reproduce

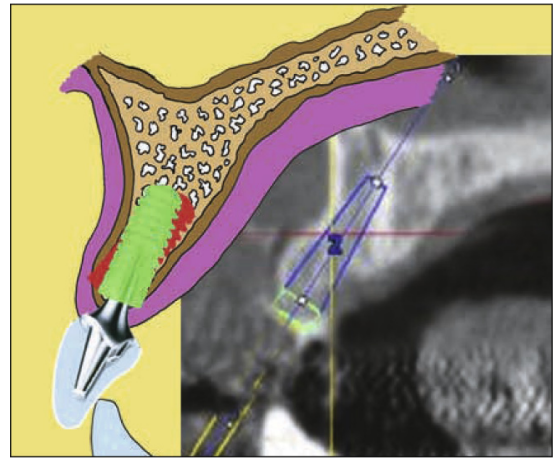

Figure 7

The scanner image and a schematic representation of a section at the level of the maxillary canine. The implant, in green, is well placed but the implant in red is too buccal, Even if an angulated post could correct the axis of the prosthesis, it emergence in the gingiva would be unsightly and the future of the buccal soft tissues uncertain.

the planned placement in the mouth operatively ${ }^{4,26}$. More than the angulation itself, which, if not precisely what it ought to be, can be corrected with an angulated post, is the precise spot of the implant's emergence, which will determine the success or failure of the implant/prosthetic replacement of a missing canine ${ }^{6,7}$. (fig. 8, 9, 10, 11).

Because the aesthetic immediate loading of a crown is not without risk during the first few weeks of the osteo-integration of an implant placed in a maxillary canine site practitioners should try to protect it from all occlusal constraints during this critical period. But this is rarely possible because of the functional role this tooth is destined to play.

But dentists can also rehabilitate a missing upper cane with a removable prosthesis. However this type of restoration has many drawbacks, the unsightly buccal clasps that have to be 
Figure 8

A perfectly positioned implant at the site of the upper right cuspid (A case treated by Dr. Jean Lecerf).
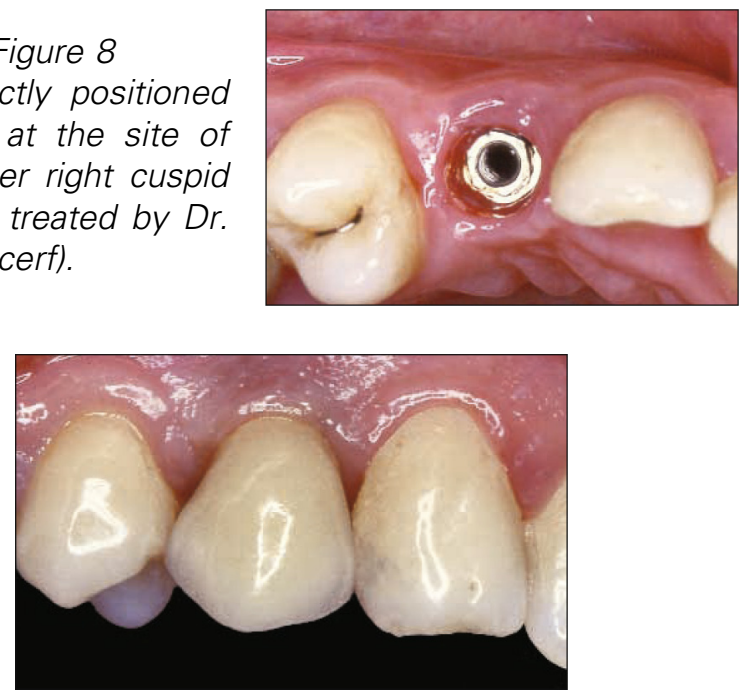

Figure 10

The amount of buccal soft tissue is great enough to give a natural appearance to the emergence of the artificial crown on the post.

used for its retention and the preparation of occlusal rests that have to be made on adjacent teeth especially those on lateral teeth, which are ill suited to support the impact of constraints on the region of their cingulums. Perhaps more troubling is the required design of the frame of the partial denture that has to extend throughout almost the full extent of the upper arch to seek a hypothetical retention on the second or even third molar on the contra-lateral side.

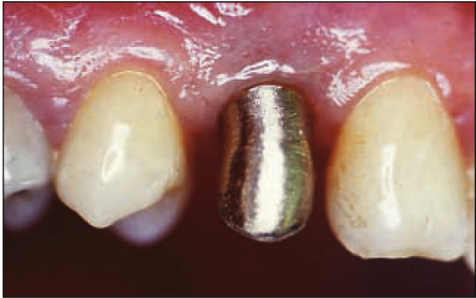

Figure 9

After the implant post has been set in position, the dentist can try on the metallic inner portion of the crown.

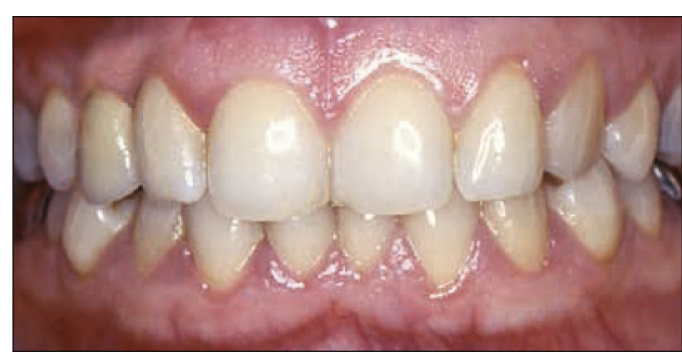

Figure 11

Intra-oral frontal view of the arch.

Prosthodontists will find the ensemble of these requirements difficult to satisfy in their attempt to produce a partial denture serving a canine function that won't be too readily dislodged and whose relation to the natural gingival tissues will not be unsightly. So partial dentures designed to replace single missing maxillary canine teeth are of distinctly marginal utility. On the other hand, when many maxillary teeth are missing many prosthodontists today still believe that removable partial dentures are often fully indicated to replace them.

\section{4 - REHABILITATION OF A MISSING CANINE IN AN ARCH WITH NUMEROUS MISSING TEETH}

Even today, the many perceived medical, anatomic, or financial disadvantages of prosthetic therapy based on implants persuade some patients to prefer removable partial dentures to replace missing teeth.
Since the work of Picton and Wills $^{41}$, who demonstrated the viscoelastic properties of the periodontal ligament and the mucous membrane, the reliance on clasp retained partial dentures built on rigid metal frames 
has been replaced with a new concept that, while retaining some of the positive features of the traditional partial dentures, distributes occlusal forces not just to supporting teeth but also to osteo-mucous structures, the partial use of rigid frames, and patient's not wearing the partial full time. These principals relegate the removable plastic partial denture without tooth born clasp support to a provisional status.

In determining how to replace missing teeth, practitioners must first fully understand the complexity and the difficulties they will encounter in treatment. In effect, when a fixed prosthesis fails, this outcome is usually immediately and obvious. But the failure of a removable partial denture may be undetectable when it is first worn and show up only later. In addition, in contrast to a widespread notion, just as much precision is called for casting the metal frame of a partial than it is for casting a fixed bridge. Finally, the difference in compressibility of osteomucosal structures and teeth, which are the elements that support a removable partial denture, add to the difficulties of treatment a need for exquisitely sophisticated impression taking that is not required for either fixed bridgework or total partial dentures.

The key element in the success of a maxillary partial denture is whether or not proper canine function can be maintained. The second depends on dentists seeing patients frequently for check-up visits and on patients following a good oral hygiene regimen.

The loss of a canine tooth always complicates the prognosis for treatment of arches with numerous missing teeth with partial dentures. Only the robust health of the remaining teeth in a healthy periodontium as well as a robust ridge in the edentulous areas can assure successful rehabilitation with an extended removable denture that will function well and not cause iatrogenic damage (fig. 12 and 13).

When a canine is lost to an arch that has already had multiple extractions, dentists must consider the advisability of making it completely edentulous so that a full and not a partial denture can be constructed.

In effect, the desired goal in such cases is not an effective prosthesis nor well executed prosthetic treatment, but durable rehabilitation and return to good function. Thinking in this way, dentists should always consider that patients with multiple missing teeth might be better off if they were completely edentulous. The worst strategy is to keep an extensive

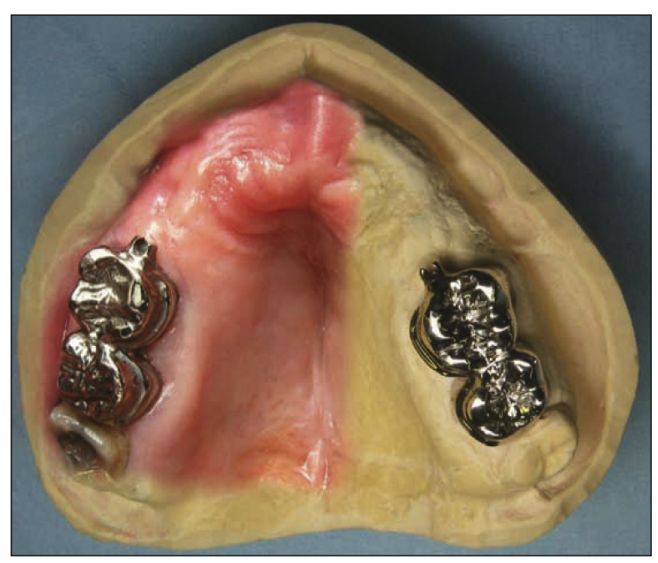

Figure 12

Placement on a model made of an impression of a partially edentulous arch showing the left and right first and second molars with anatomically prepared crowns splinted together with supporting matrices for resilient function, stress-breaking ASC52 attachments. The alveolar ridge is robust and the palate deep making retention of the partial ideal and allowing for re-creating bilateral canine functioning without difficulty. 


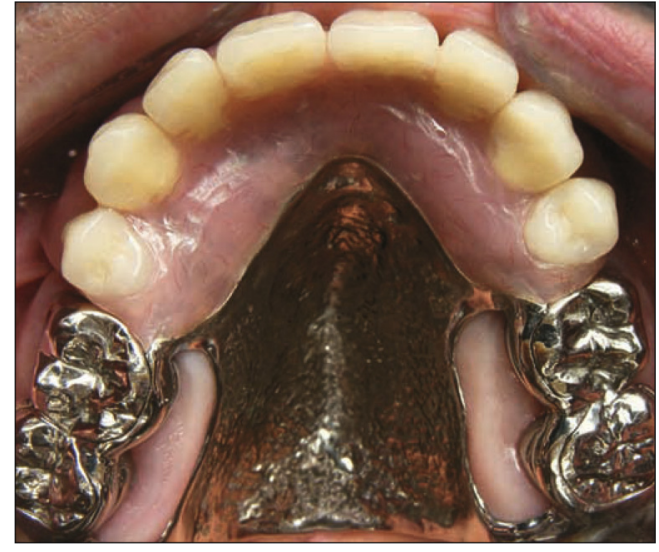

Figure 13

Intra-oral view of metal frame removable partial denture in place. Note how precisely it is adapted to the mucosa and to the metal crowns. The rigid arms of the clasps and the crown bars fit well in the palatal shapes of the crowns that have not been over-contoured.

partial denture retained by a few remaining teeth in a periodontium of doubtful quality at any cost until the final days when the last feeble tooth must be extracted. In these situations, patients, often well on in years, will finally have to submit to the always difficult learning curve of dealing with a full denture. The best strategy is to to prepare the remaining teeth in their weakened periodontium endodontically so that they can eventually support post attachments to anchor a full denture (fig. 14, 15, 16, 17).

Practitioners should attempt to preserve the roots of a patient's last remaining teeth even ones in an unfavourable periodontal environment because they will bestow an intact proprioception to a future denture and help the patient to masticate without insurmountable difficulty thanks to the sensory-motor interactions of their periodontal receptors. These patients will not have to undergo the brutal relearning curve of how to chew again. Even if those enfeebled residual roots

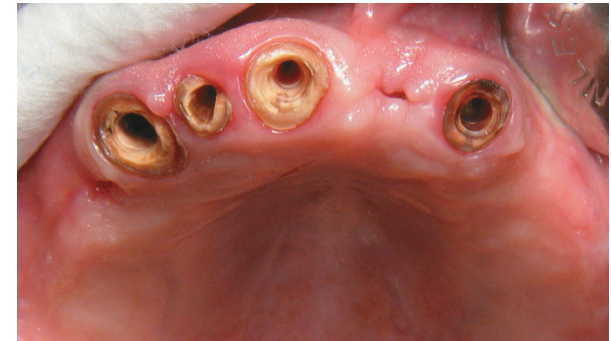

Figure 14

These four seriously broken down teeth, in an otherwise edentulous arch, were preserved to maintain their periodontal proprioception.

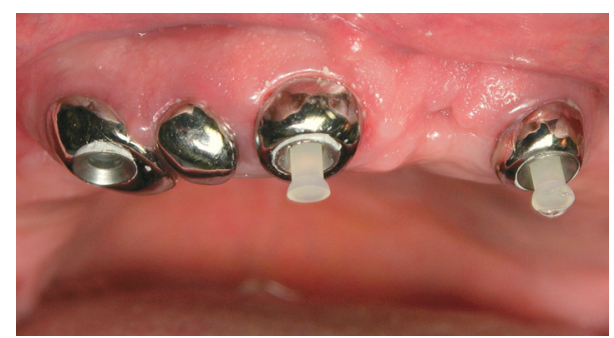

Figure 15

Their residual roots received copings that would support ZAAG overdenture attachments for the upper right canine and central and the left central and a simple cap for the left lateral. Once the copings are cemented to the roots, the male parts, in nylon, are placed in the matrices of the full denture and, covered in resin, are set into the copings. While bonding is setting in the moth the patient maintains pressure by biting on the denture.

survive for only a few months under a new full denture, the progressive loss of sensory receptors as the periodontium fades away will ease the passage of patients from a lifetime of chewing with teeth to a new status of masticating with dentures. Then, on the day when their last remaining teeth, other than the treated roots, have to be extracted their neuromuscular systems will already have made the necessary adjustments and the simple insertion of the male part of the attachment into the underside of 


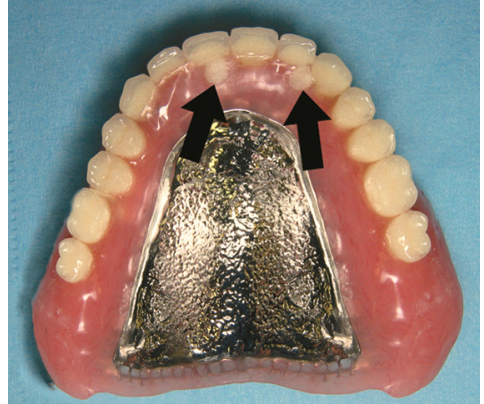

Figure 16

The complete tooth-bone-mucosa supported full denture shows in its outer surface traces (black arrows) of the excess of the self-polymerising resin that bonded the male parts of the retention apparatus to the denture except in the canine area where the acrylic is too thick and the bonding succeeded without any perforation of the denture. The attachments amplify the denture's natural retentive qualities and because of the remaining root structures greatly enhance its proprioceptive performance.

the denture will suffice to maintain the functional effectiveness of the full denture made months or even years earlier.

The teeth the most suitable for this over-denture concept, now referred to as a complete tooth-bone-mucosal supported full denture are the upper central incisors, the upper and lower premolars and molars, and, especially, the upper and lower canines. These are the teeth the most richly endowed with sensory receptors and they are often the last ones remaining in the arch.

The treating dentist will always try to maintain symmetry on both sides of the midline in choosing teeth to support an over-denture. So if only a few teeth persist on only one side of the arch the dentist should extract them rather them than use them to support an over-denture that will inevitably suffer from uni-lateral mastication provoked by uni-lateral pro-

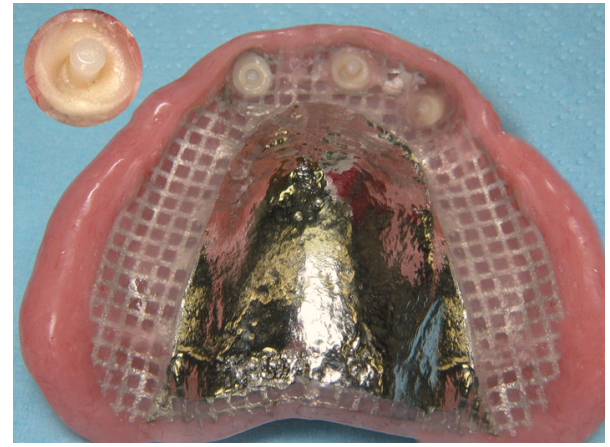

Figure 17

The underside of the denture shows the male parts of the attachments enveloped in their bonding base. An enlargement of the attachment in canine area is shown in the upper left.

prioception. The occlusal concept that dentists should systematically bear in mind for this type of mastication is the permanence of bi-lateral contacts in lateral movements and antero-posterior contacts in propulsive movement, which is to say a balanced bi-lateral occlusion.

Of course implant-based prosthetic therapies, when they are indicated, can take the place of a few remaining teeth, after they have been extracted, and act as substitutes for them in partial denture rehabilitation.

In the mandible, by placing two implants, at the canine sites, dentists can insure that a full over-denture will be stable and retentive. This is the minimum reference standard as established by a 2002 conference at McGill University in Montreal. By following this protocol dentists can fabricate reliable full lower dentures in a straightforward fashion at a moderate price $^{28}$ (fig. 18, 19). In the maxilla the extensive supporting area supplied by the palate as well as ridges that are sturdier than those in the mandible make the need for implant 


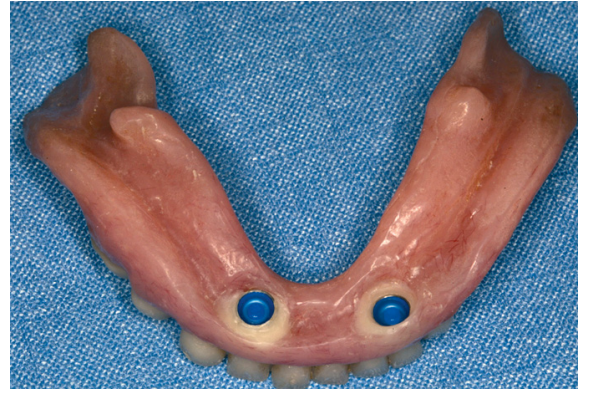

Figure 18

A complete lower denture stabilised by two implants. The matrix of the Locator $^{\circledR}$ attachments is clearly visible on the denture's underside.

supported full dentures far less frequent.

Where indicated, when the amount of resorption and the crown height remain adequate, dentists can construct conventional implant supported bridges $^{4}$. In these cases implants are positioned in selected sites, usually the regions of the central incisors, the canines, and sometimes premolars and molars, in such a way as to allow the prosthetic posts to suit the patient's periodontium. When serious gingival and mucosal resorption has

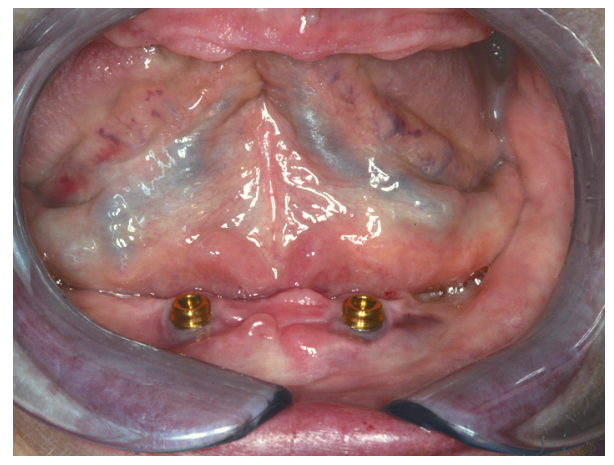

Figure 19

A view of the male parts of the denture attachments emerging from two implants set in the sites of the lower canines. occurred that would require long posts and an unsightly bridge with an unfavourable crown/implant ratio the concept of "all-on-four" bridge introduced by Dr. Paulo Malo around 2000 may be indicated. This type of implant supported bridge uses artificial acrylic gingiva around prosthetic teeth that are carried by a metallic frame inserted into implants that do not necessarily follow the emergence path of the natural teeth they replace $29,33,34$ With this technique the two posterior implants can be inclined distally so they don't risk impinging on critical zones like the mandibular canal and the maxillary sinus. This increases initial stability and allows the dentist to place an immediate full denture supported by four implants on the day of surgery $^{33,34}$ (fig. 20, 21, 22, 23, 24). This extensive type of rehabilitation presupposes durable osteo-integration of the four implants. If just one of them fails, this will compromise the entire enterprise. So dentists have to consider using rehabilitation techniques with a greater margin of error on posts placed in 6 to 8 implants in which the entire project will not have

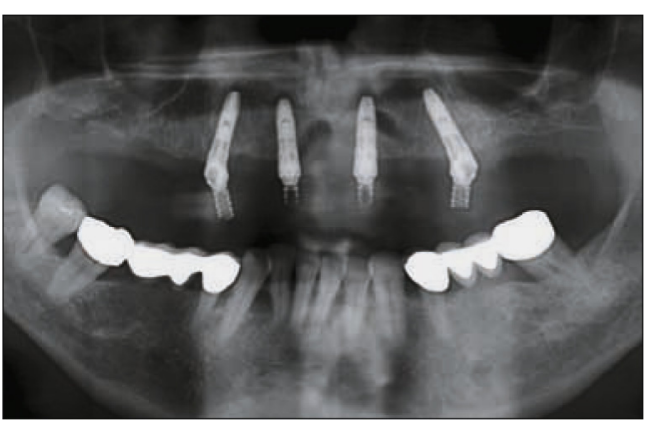

Figure 20

The all-on-four technique. The four upper implants in place with their provisional posts (Dr. Jean Lecerf's case. Dr. Patrick Limbourg did the surgery). 


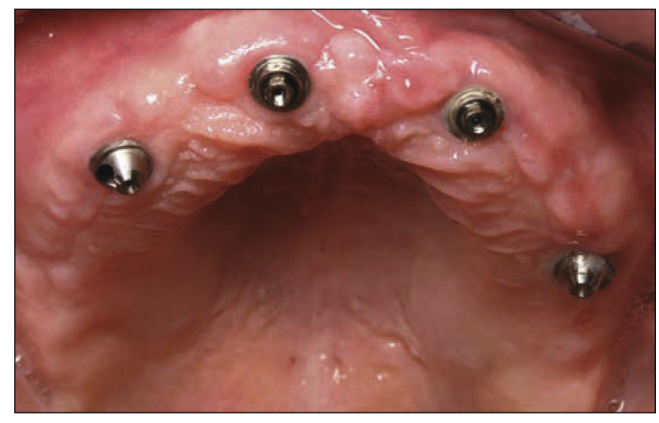

Figure 21

The emergence of the implants and the multi-unit posts (Nobel Biocare ${ }^{\circledR}$ ) fifteen days after the non-flap surgery that left no gingival scarring.

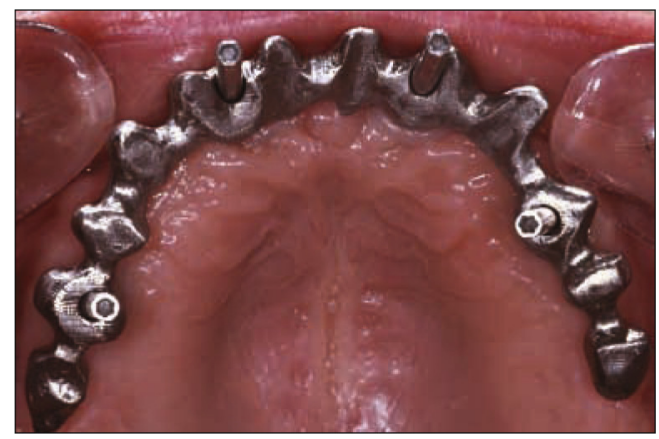

Figure 22

Try-on of the metal frame on the final posts.

to be abandoned just because one of the implants fails. But this more prudent approach will cost more while providing the same same functions ${ }^{38}$. The extensive implant supported reconstructions, whether they function in immediate or delayed canine disocclusion or in group function, impose the equivalent constraints on the implants and their superstructures. Because of this dentists should make a choice of the dynamics of occlusion based more on the character of the opposing arch than on the arch that will be restored with a partial denture $24,35,37,39$ (table 1).

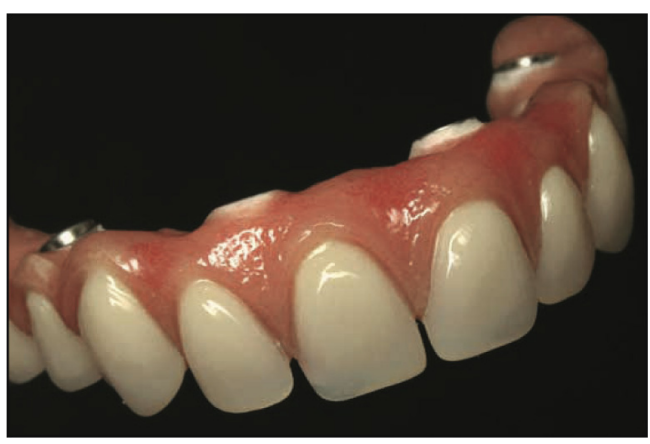

Figure 23

The bridge with false gingiva and plastic teeth llab technician Yves Gastard).

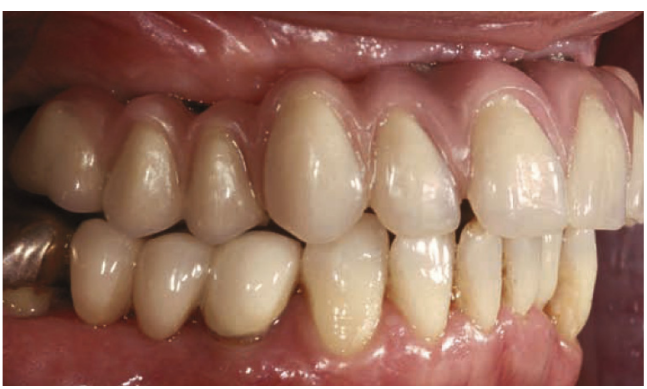

Figure 24

Bridge in place in the mouth. Note the spaces above the false gingiva that are indispensable for good oral hygiene but that sometimes interfere with patients pronouncing words properly. Unlike a dentition with a healthy periodontium and natural canines in place, this artificial denture functions with the false canines out of occlusion in lateral movements.

\section{Cases of extensive tooth loss}

When dentists cannot restore the function of a missing canine with a partial removable denture because the anatomy of the ridge would not provide it with sufficient stability and retentivity, they must consider fabrication of implant supported prosthesis.

But because an osteo-integrated implant is not housed in a periodontal membrane it does not have the resilience of a natural tooth, the 


\begin{tabular}{|c|c|c|c|c|c|c|}
\hline $\begin{array}{l}\text { Arch } \\
\text { opposing } \\
\text { bridge }\end{array}$ & $\begin{array}{c}\text { Full } \\
\text { denture }\end{array}$ & $\begin{array}{l}\text { Partial } \\
\text { denture } \\
\text { Anterior } \\
\text { teeth } \\
\text { including } \\
\text { canines } \\
\text { missing }\end{array}$ & $\begin{array}{c}\text { Partial } \\
\text { denture } \\
\text { Anterior teeth } \\
\text { missing but } \\
\text { natural } \\
\text { canines in } \\
\text { place }\end{array}$ & $\begin{array}{c}\text { Partial } \\
\text { denture } \\
\text { Right and } \\
\text { left buccal } \\
\text { teeth, } \\
\text { including } \\
\text { canines } \\
\text { missing } \\
\text { place }\end{array}$ & $\begin{array}{l}\text { Partial denture } \\
\text { Right and left } \\
\text { buccal teeth } \\
\text { missing but } \\
\text { natural canines } \\
\text { still in place }\end{array}$ & $\begin{array}{l}\text { Full arch of } \\
\text { natural teeth or } \\
\text { fully rehabilitated } \\
\text { with fixed } \\
\text { bridges }\end{array}$ \\
\hline
\end{tabular}

Table 1

Indication of occlusal dynamics that focuses more on the opposite arch than on the arch being reconstructed with a removable partial denture.

differential in the response of tissues investing implants and natural poses a problem to dentists planning a mixed implant-tooth born prosthesis: should the restoration connect the natural and artificial roots?

A thoughtful review of the literature $31,35,44,45,54,57$ would lead a reader to answer that question with a "no." Still, some authors recommend such a union and many such restorations have lasted for years, but no statistics for the failure rates of connected and nonconnected prostheses are available.

So it is really not possible to propose an all inclusive answer because very case has its own unique clinical indications. A prosthesis supported by multiple implants risks making the natural teeth to which they are joined by a cantilever-type bar an extension of themselves (fig 25). To avoid this, the connector should be semi-rigid with a flexible interrupter of forces placed as closely as possible to the implants to reduce the amplitude of the lever arm. The case shown in figure 25 can be compared to the one depicted in figure 12. These two types of Class IV maxillary edentulousness would seem to be similar but the shallowness of

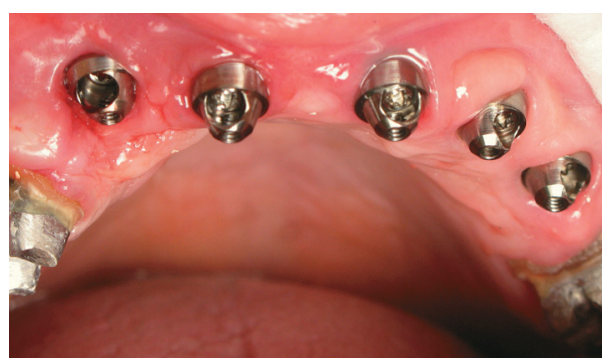

Figure 25

Five short implants were placed in the highly resorbed anterior sector of the maxillary ridge to support a bridge on posts that replaced a removable partial denture that had functioned poorly. The multi-unit posts (Nobel Biocare ${ }^{\circledR}$ ) can be seen emerging from the freshly healed gingiva. The natural posterior teeth rehabilitated with inlay-cores were prepared to receive splinted crowns (Dr. Anne-Laure Auroy-Guillot did the surgical procedure). 


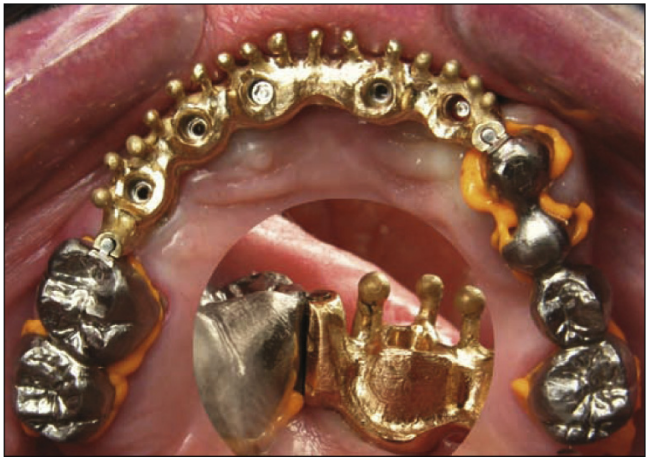

Figure 26

Try-on of partial denture frame and the tooth supported fixed prostheses. The semi-grid connectors bind the two types of prosthetic appliances together while allowing periodontal play under the tooth supported sectors and also contributing to the appliance's capacity to resist the horizontal constraints transmitted to the short implants. In the inset is a palatal view of the semi-rigid connector mesial to the upper right first molar. (Christophe Flabeau is the dental technician who fabricated the prosthesis.)

the ridge offered feeble retention to a removable partial denture in the second case. Accordingly, the treating dentist had to construct an implant supported

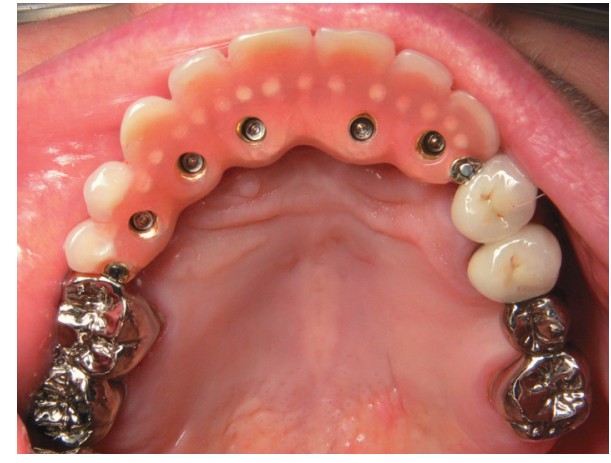

Figure 27

Intra-oral view of the reconstruction in place. This type of design allows for a canine-protected occlusion whose constraint on the prosthesis do not dislodge it during lateral or propulsive excursions as was the case when the patient wore a partial removable denture.

denture. Its semi-rigid connector with sliding grooves allowed for periodontal play in its tooth supported sectors and also contributed to its capacity to resist the lateral and anterior constraints the implant supported sector was subjected to (fig. 25, 26, 27).

\section{5 - REHABILITATION OF A BROKEN-DOWN CANINE IN AN ARCH WITH MANY MISSING TEETH}

Full arch or nearly full arch reconstruction is no longer difficult to achieve so long as the canines can be restored whether the bridge is supported entirely by natural teeth or by a combination of natural teeth and implants. Dentists will usually achieve success if they have restored the patient's periodontium to good health and if they have respected the type and quality of the tooth-prosthetic joint as stipulated in the principles outlined above and in fig. 28, 29, and 30 .

They should have reduced the size of the inlay-core preparations enough to allow for the placement of crowns and their cosmetic coverings that would harmonise with the proportions of the original natural teeth and their emergence from the gingive ${ }^{27}$. They should also constructed the restorations in such a way that they will have contact points just above the gingiva and will be convex enough to allow patients good access for the maintenance of effective oral hygiene. It is also crucial for dentists to construct rehabilitations that will have scrupulous respect for occlusal dynamics by having registered them and mounted 


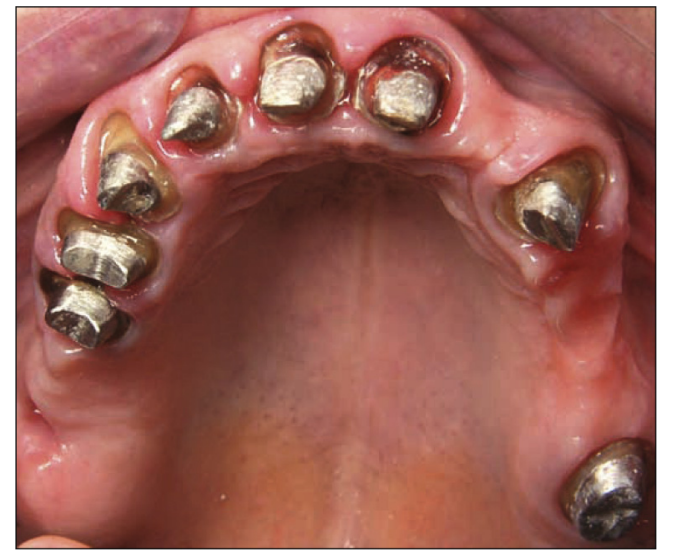

Figure 28

Fixed rehabilitation of a broken down maxillary canine. Because both canines were present the prosthodontist was able to fabricate a full arch bridge without using implants. The prosthodontist restored the periodontium to a healthy condition and carefully respected it during tooth preparation, which facilitated the next chair side steps including impression taking, try-ons, occlusal adjustments, and cementation.

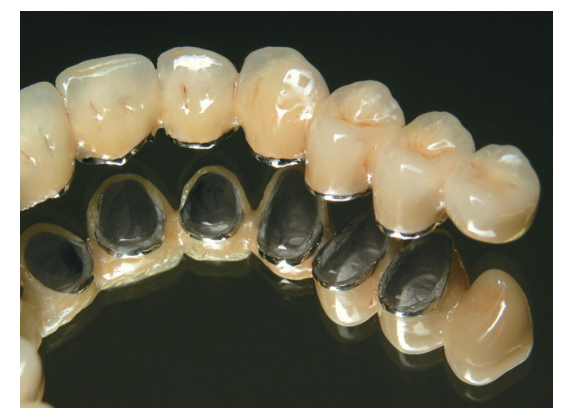

Figure 29

Mirror view of the prosthesis. Note the ceramic-tooth joints for the incisor canine group and the metal-tooth joints in the bicuspid molar area (dental technician Jean-Chritophe Flabeau).

them on articulators to determine condylar inclination and Bennet's angle. Finally, for rehabilitation of an entire arch dentists must make a therapeutic choice of occlusion: maximal inter-cuspation in centric occlu-

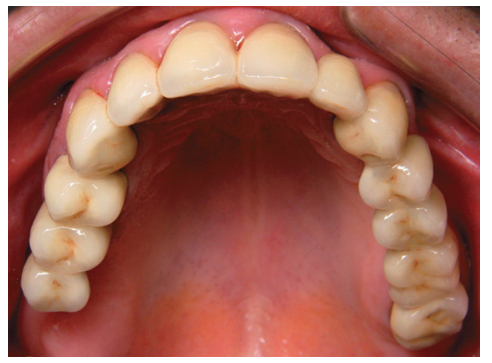

Figure 30

The ceramic crowns had enough bulk for the technician to give them a life-like appearance and a natural looking emergence from the gingiva.

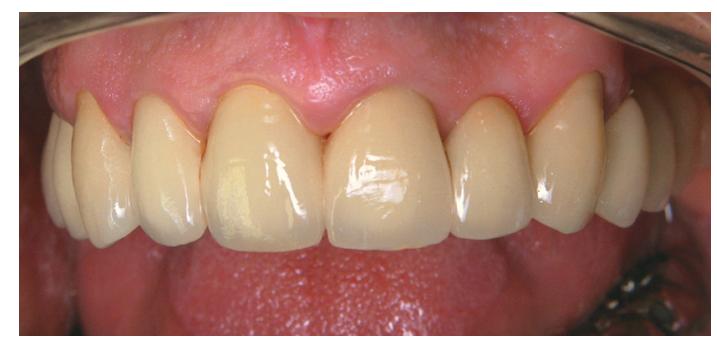

Figure 31

At six months the prosthesis appears well integrated

sion, because that is the only that they can re-register over the course of treatment. They should also, in most cases, instead of group function, select canine protected occlusion in lateral movements as well disengagement of the buccal teeth by the protection of the group of incisors and canines in propulsive movements. Of course, they must adjust these principles when the condition of the opposing jaw requires it (cf. table 1).

Under these conditions, the biological and functional integration of a fixed, multi-unit rehabilitation of a broken down canine will be assured.

These principles also apply in the rehabilitation of a broken down canine by a multi-unit partial removable prosthesis. 


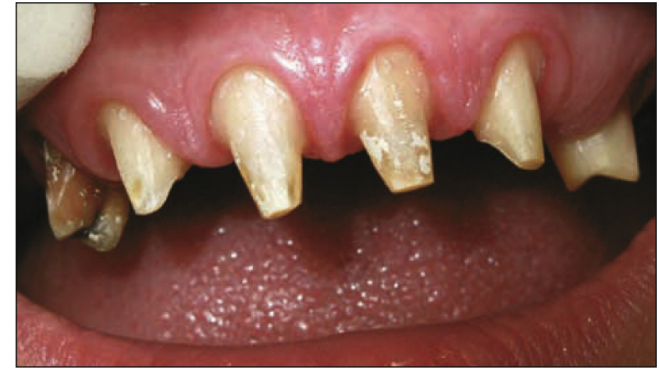

Figure 32

This older patient was unhappy with the effect the congenital absence of her upper lateral incisors had on the appearance of her smile. But she was unwilling to undergo orthodontic treatment to correct the problem. So we prepared her vital central incisors, canines, and premolars to receive crowns.

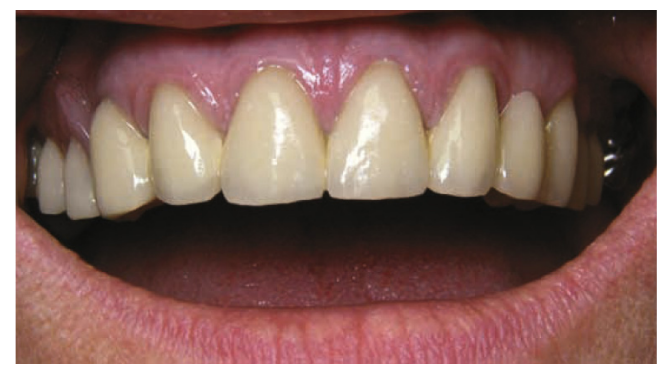

Figure 34

This intra-oral view shows the excellent aesthetic integration of the fixed anterior bridge and the removable partial denture (ceramicist Jean-Paul Lauremboule, frames of the two prostheses by technician Bruno Charbonier).

These extensive rehabilitations that often incorporate broken down canines and other teeth adjacent to the edentulous sites into fixed bridges associated with recoverable partial dentures are sometimes referred to as "combined prostheses" but instead of this outdated nomenclature we prefer the term "composite prostheses" because composed as they are of conjoined elements like those in composite fillings they have in their ensemble characteristics superior to

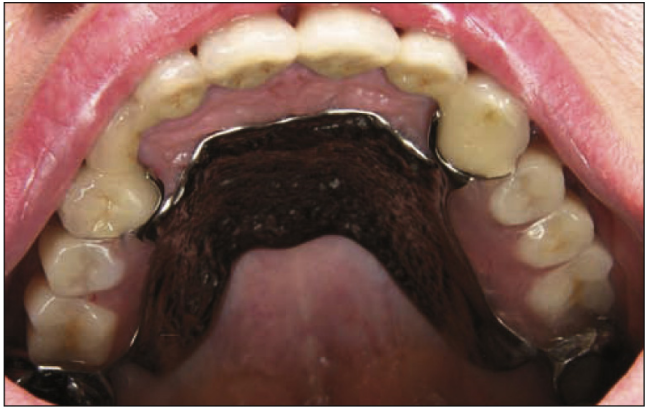

Figure 33

We made an anterior bridge for her in which her incisors, canines, and premolars were splinted together to improve her smile and to articulate by means of invisible ASC52 attachment with a removable posterior partial denture.

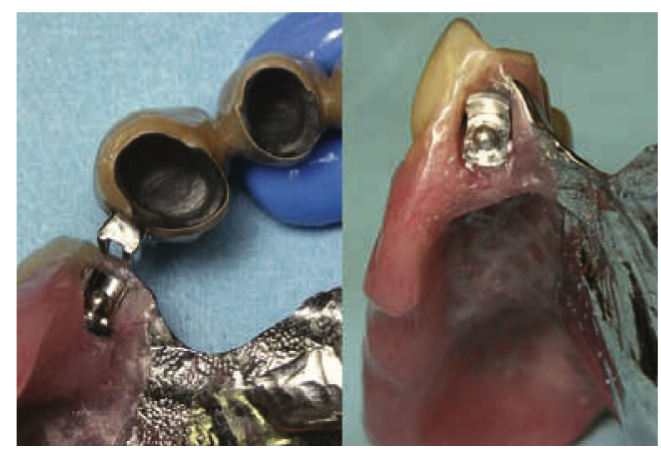

Figure 35

At the left a view of the underside and the male part of the attachment in the facing of the matrix splinting the frame of the partial with the fixed anterior bridge. At the right the attachment is entirely embedded in the premolar sector of the removable partial so that it is completely invisible when the partial is in place in the mouth.

those that would have been achieved if their components operated individually side by side.

These reconstructions also have to react to the different compressibility of the structures that support them. In effect, the periodontal compressibility of the fixed elements of the composite prosthesis is on the order of 100 microns while the mucosal 
compressibility of the tissues beneath the removable elements can be greater than one millimeter. Under these varying conditions in order for occlusal constraints to be harmoniously distributed throughout the composite prosthesis between bone and soft tissue supporting areas the dentist must employ accurate sophisticated impression techniques. The over-all composite impression, as its name suggests, may be composed of three or four different materials used successively in an individualized impression tray. Or the dentist may choose to employ the correction impression described by McCracken that utilizes the metal frame of the removable partial denture made from the initial impression as an impression tray in order to register secondarily the varying compressibility of mucosa and of teeth.

These metal frames are often constructed to articulate with conjoined elements by means of attachments that are machine made clasps that must, like all clasps, serve the triad of the equilibrium of partial dentures as

\section{6 - CONCLUSION}

There is always an element of risk in the rehabilitation of canine teeth heightened by the importance of the aesthetic and functional roles they play.

Even though dentists can expect that the reconstruction of broken down canines usually enjoys a good prognosis, they must remember that the loss of this "keystone of the dental arch" would pose numerous problems and complicate therapy. described by Housset: retention, stability, and support.

The position of the canine in the arch in addition to the strength of the anchorage provided by its sturdy root make it an ideal pillar to sustain the attachments of partial dentures. Even so, canines are not sufficiently unmovable to resist indefinitely the constraints that those machine made clasps will subject them to. Accordingly, dentists should routinely splint reconstructed canines to fixed bridges constructed on other rehabilitated adjacent teeth so that occlusal forces can be distributed to this consolidated group as well as to the conjoined partial denture.

The principal benefit derived from laboratory fabricated attachments over factory made clasps, in addition to their improved retention capacities, is undoubtedly aesthetic. But the forces they transmit to the dento-periodontal structures are so great that dentists should be sure that the quality and the number of the roots supporting them are capable of resisting those constraints (fig. 3, 33, 34, 35).

But, whatever the complexity and the extent of the rehabilitation processes, only by taking into account the over-all value of the canine in the oro-facial complex, and particularly its periodontal, occlusal, and functional aspects, can dentists accurately assess all the diagnostic issues and make the proper decisions that will lead to clinical success. 
BIBLIOGRAPHY

1. ANAES: Indications et contre-indications des reconstitutions corono-radiculaires préprothétiques coulées et insérées en phase plastique. Service d'évaluation technologique, 2003.

2. Andersson M, Razzoog ME, Oden A, Hegenbarth EA, Lang BR. Procera: a new way to achieve an all-ceramic crown. Quintessence Int 1998;29(5):285-96.

3. Akca K, Uysal S, Cehreli MC. Implant-tooth-supported fixed partial prosthèses: correlations between in vivo occlusal bite forces and marginal bone reactions. Clin Oral Impl Res 2006 Jun;17(3):331-6.

4. Balmer S, Mericske-Stern R. Implant-supported bridges in the edentulous jaw. Clinical aspects of a simple treatment concept. Schweiz Monatsschr Zahnmed 2006;116(7):728-39.

5. Bolla $M$, Bennani $V$. La reconstruction corono-radiculaire pré-prothétique des dents dépulpées. Guide clinique. Editions CdP.

6. Cardaropoli D, Debernardi C, Cardaropoli G. Immediate placement of implant into impacted maxillary canine extraction socket. Int J Periodontics Restorative Dent 2007 Feb;27(1):71-7.

7. Chiapasco M, Zaniboni M. Clinical outcomes of GBR procedures to correct peri-implant dehiscences and fenestrations: a systematic review. Clin Oral Implants Res 2009 Sep;20 Suppl 4:113-23.

8. CovoL. Reconstitutions corono-radiculaires et facteurs influençant leur rétention Revue Française d'Odonto-Stomatologie 2000;29(1).

9. de Oliveira RR, Novaes AB Jr, Papalexiou V, Muglia VA, Taba M Jr. Influence of interimplant distance on papilla formation and bone resorption: a clinical-radiographic study in dogs. J Oral Implantol 2006;32(5):218-27.

10. Diaz-Arnold AM, Vargas MA, Haselton DR. Current status of luting agents for fixed prosthodontics. J Prosthet Dent 1999;81(2):135-41.

11. Dietschi D, Duc O, Krejci I, Sadan A. Biomechanical considerations for the restoration of endodontically treated teeth: a systematic review of the literature - Part1. Composition and micro- and macrostructure alterations.Quintessence Int 2007;38(9):733-43.

12. Dietschi D, Duc O, Krejci I, Sadan A. Biomechanical considerations for the restoration of endodontically treated teeth: a systematic review of the literature, Part II (Evaluation of fatigue behavior, interfaces, and in vivo studies). Quintessence Int 2008;39(2):117-29.

13. Donovan TE. Factors essential for successful all-ceramic restorations. J Am Dent Assoc 2008 Sep;139 Suppl:14S-18S.

14. Dong J, Ikebe K, Gonda T, Nokubi T. Influence of abutment height on strain in a mandibular overdenture. J Oral Rehabil 2006 Aug;33(8):594-9.

15. Dragoo MR et Williams GB. Periodontal tissue reactions to restorative procedures. Int J Periodont Rest Dent 1981;1:9-23.

16. Dwan A, Yaman P, Razzoog ME, Wang RF. Effect of cement on fracture: resistance of all-ceramic crowns. J Dent Res 1996; 75(abstr 2136):284.

17. Eames W'B, O'Neal SJ, Monterio J, Miller C, Roan JD et Cohen KS. Techniques to improve the seating of castings. J Amer Dent Ass 1978;96:432-7.

18. Fasbinder DJ. Clinical performance of chairside CAD/CAM restorations. J Am Dent Assoc 2006 Sep;137 Suppl:22S-31S.

19. Felton DA, Kanoy BÉ, Bayne SC et Witrhman GP. Effect of in vivo crown margin discrepancies on periodontal health. J Prosth Dent 1991;65:357.

20. Fleiter B, Martin D. Critères d'intégration parodontal et esthétique des constructions céramiques antérieures. Journal de parodontologie Vol14, № 2/95:215-24.

21. Gantel C, Aboudharam G, Déjou J, Blanchard JP. Enquête sur la pratique des reconstitutions corono-radiculaires. Cahiers de prothèse 2006;133:21-9. 
22. Gargiulo AW, Weintz FM, Orban B. Dimensions and relations of the dento gingival junction in human. J Periodont 1961;32:261-7.

23. Hegenbarth E. Use of the Procera CAD/CAM System for metal-free crowns on singletooth implants. Quintessence Dent Tech 1998;1:27-37.

24. IsidoriM, MalquartiG, ChavrierC. Concepts occlusaux en prothèse fixée implantaire. Implant 1998;4(1):29-40.

25. Joe Editorial Board. Restoration of the endodontically treated tooth: an online study guide. J Endod 2008 May;34(5 Suppl):e187-90.

26. Jung RE, Pjetursson BE, Glauser R, Zembic A, Zwahlen M, Lang NP. A systematic review of the 5-year survival and complication rates of implant-supported single crowns. Clin Oral Implants Res 2008 Feb;19(2):119-30. Epub 2007 Dec 7.

27. Knode H, Sorensen JA. Fracture strength of ceramic single tooth implant restoration. J Dent Res 1992;71(abstr 1137):248.

28. KrennmairG, WeinländerM, Krainhöfner M, PiehslingerE. Implant-supported mandibular overdentures retained with ball or telescopic crown attachments: a 3-year prospective study. Int J Prosthodont 2006 Mar-Apr;19(2):164-70.

29. Lai YL, Chou IC, Liaw YC, Chen HL, Lin YC, Lee SY. Triple immediate therapy (ridge expansion, soft tissue augmentation, and provisional restoration) of maxillary anterior single implant. J Periodontol 2007 Jul;78(7):1348-53.

30. Larson TD. Part two: The restoration of non-vital teeth: structural, biological, and micromechanical issues in maintaining tooth longevity. Northwest Dent 2006;85(6): 23-5, 27, 29-32.

31. Le Gall MG, Saadoun AP. Liaison entre dents naturelles et implants. Limites et indications. Cah Proth 2004;127:17-28.

32. LundgrenD. Prosthetic reconstruction of dentitions seriously compromised by periodontal disease. J Clin Periodontol 1991 Jul;18(6):390-5.

33. Maló $P$, Rangert $B$, Nobre M. "All-on-Four» immediate-function concept with Brånemark System implants for completely edentulous mandibles: a retrospective clinical study. Clin Implant Dent Relat Res 2003;5 Suppl 1:2-9.

34. Maló P, Nobre Mde A, Petersson U, Wigren S. A pilot study of complete edentulous rehabilitation with immediate function using a new implant design: case series. Clin Implant Dent Relat Res 2006;8(4):223-32.

35. Mariani P, Margossian P, Labprde G. Choix d'un concept occlusal en implantologie. 1re partie: données fondamentales. Stratégie Prothétique 2008;8(1):5-13.

36. Marshall B F. Reconstitution des dents après traitement endodontique. Revue de parodontie et de dentisterie restauratrice 7-29.

37. OrthliebJD, BrocardD, SchittlyJ, Manière-EzvanA. Occlusodontie pratique. Paris: CdP 2000;210p.

38. OyamaK, KanJY, KleinmanAS, Runcharassaeng K, Lozada JL, Goodacre CJ. Misfit of implant fixed complete denture following computer-guided surgery. Int J Oral Maxillofac Implants 2009;24(1):124-30.

39. Okano N, Baba K, Igarashi Y. Influence of altered occlusal guidance on masticatory muscle activity during clenching. J Oral Rehabil 2007;34(9):679-84.

40. Persson GR. Perspectives on periodontal risk factors. J Int Acad Periodontol 2008 Jul; 10(3):71-80.

41. Picton DC, Wills DJ. Viscoelastic properties of the periodontal ligament and mucous membrane. J Prosthet Dent 1978;40(3):263-72.

42. Pjetursson BE, Sailer I, Zwahlen M, Hämmerle $\mathrm{CH}$. A systematic review of the survival and complication rates of all-ceramic and metal-ceramic reconstructions after an observation period of at least 3 years. Partl: Single crowns. Clin Oral Implants Res 2007 Jun;18 Suppl 3:73-85. Erratum in: Clin Oral Implants Res 2008;19(3):326-8.

43. Pjetursson BE, Brägger U, Lang NP, ZW Ahlen M. Comparison of survival and complication rates of tooth-supported fixed dental prostheses (FDPs) and 
implant-supported FDPs and single crowns (SCs). Clin Oral Implants Res 2007 Jun;8 Suppl 3:97-113. Erratum in: Clin Oral Implants Res 2008;19(3): 326-8.

44. RangertB, GunneJ, Glantz PO, Svensson A. Vertical load distribution on a three-unit prosthesis supported by a natural tooth and a single Brånemark implant. An in vivo study. Clin Oral Impl Res 1995;6(1):40-6.

45. RangeriB. Biomécanique des implants de Brånemark. Implant 1995;1(1):63-74.

46. Samama Y, Ollier J. La prothèse ceramo-ceramique et implantaire. Réussir Quintessence éditeur.

47. Sarment DP, Meraw SJ. Biological space adaptation to implant dimensions. Int J Oral Maxillofac Implants 2008;23(1):99-104.

48. Sadowsky SJ. An overview of treatment considerations for esthetic restorations: a review of the literature. J Prosthet Dent 2006;96(6):433-42.

49. Sailerl, Pjetursson BE, Zwahlen M, Hämmerle $\mathrm{CH}$. A systematic review of the survival and complication rates of all-ceramic and metal-ceramic reconstructions after an observation period of at least 3years. Part II: Fixed dental prostheses. Clin Oral Implants Res 2007 Jun;18 Suppl 3:86-96. Erratum in: Clin Oral Implants Res 2008;19(3):326-8.

50. Serfati E, Decloquement C, Radiguet J. Les préparations corono-radiculaires des dents dépulpées. Réalités cliniques 1996;7(4):433-46.

51. Sharkey S, Chaollai AN, O'Sullivan M. A review of aggressive periodontitis and an associated case report. Dent Update. 2009;36(1):38-40, 43-4, 47-50.

52. Spear F, Holloway J. Which all-ceramic system is optimal for anterior esthetics? J Am Dent Assoc 2008;139 Suppl:19S-24S.

53. StuderS, Pietrobon N, Wohlwend A. Maxillary anterior single-tooth replacement: comparison of three treatment modalities. Pract Periodontics Aesthet Dent 1994;6(1):51-60; quiz 62.

54. Tan K, Pjetursson BE, Lang NP, Chan ES. A systematic review of the survival and complication rates of fixed partial dentures (FPDs) after an observation period of at least 5 years. Clin Oral Impl Res 2004;15(6):654-66.

55. Viargues $P$. La position des limites cervicales de préparation en prothèse fixée. Analyse de la littérature: conséquences cliniques. Rev Odont Stomat 2005;34:3-18.

56. Wassell RW, Smart ER, St George G. Crowns and other extra-coronal restorations: cores for teeth with vital pulps. Br Dent J 2002;192(9):499-502, 505-9.

57. Zhiyong L, Arataki T, Shimamural, Kishi M. The influence of prosthesis designs loading conditions on the stress distribution of tooth-implant supported prostheses. Bull Tokyo Dent Coll 2004;45(4):213-21. 